\title{
The Characteristics and Lipid Profile Levels in Vegetarian and Non-Vegetarian Subjects - What's the Difference?
}

\author{
Muhammad Hanif Baswedan* \\ Faculty of Medicine \\ Jenderal Achmad Yani University \\ Cimahi, Indonesia \\ *baswedan.hanif@gmail.com
}

\author{
Rini Roslaeni \\ Department of Clinical Pathology \\ Jenderal Achmad Yani University \\ Cimahi, Indonesia
}

\author{
Budhi Suwarma \\ Department of Neurology \\ Jenderal Achmad Yani University \\ Cimahi, Indonesia
}

\begin{abstract}
Coronary Heart Disease (CHD) and stroke are two diseases that have high incidence rates, especially in Indonesia. One of the causes is the formation of atherosclerotic plaque in which can be characterized by an abnormal lipid profile. Lipid profile can be influenced by several factors, which are age, sex, physical activity, smoking, and especially dietary habit. A bad dietary habit: such as consuming a high fat in which can influence the blood lipid profile. The purpose of this study was to determine the characteristics and lipid profile levels in vegetarian and non-vegetarian subjects Advent Indonesia University. The method of this study was descriptive observational with a crosssectional design. The sample size of this study was 19 students of vegetarian and 19 students of non-vegetarian with $95 \%$ of $\mathrm{CI}$. The subject was chosen by the simple random sampling method. The parameters of lipid profile which were checked in this study i.e., total cholesterol, HDL, LDL, and triglyceride. Examination of lipid profile levels was done in the Clinical Pathology Laboratory of Jenderal Achmad Yani University. The study showed that mean levels of total cholesterol in group vegetarian was $155,78 \mathrm{mg} / \mathrm{dL}$, HDL was $52,85 \mathrm{mg} / \mathrm{dL}$, LDL was 90,22 $\mathrm{mg} / \mathrm{dL}$, and triglyceride was $69,80 \mathrm{mg} / \mathrm{dL}$. Based on the results of this study, it can be concluded that vegetarian and nonvegetarian subject had a normal mean level of lipid profile. Further research is needed with another design (case- control), a bigger population used, and with a different way of analysis.
\end{abstract}

Keywords-dietary habit, lipid profile, vegetarian

\section{INTRODUCTION}

The normal level of lipids in the blood certainly has an important function in the body, but abnormal levels of lipids in the blood (dyslipidemia) may lead to the formation of atherosclerosis. Atherosclerosis can cause disruption of blood flow to the arteries in the heart, brain, kidneys, and lower extremities which in turn can lead to several diseases such as coronary heart disease (CHD), stroke, and peripheral artery disease [1-4]. A person at risk for cardiovascular disease and stroke may be monitored by reviewing a lipid profile. A lipid profile is a type of examination designed to verify blood lipid levels. Common lipid profiles used for clinical purposes include total cholesterol, high-density lipoprotein (HDL), lowdensity lipoprotein (LDL), and triglycerides (TG). The lipid profile may be influenced by several factors, including age, gender, diet, physical activity, and smoking $[3,5,6]$. Maintaining a good diet, by consuming a low-fat diet that primarily contains unsaturated fats with low cholesterol levels is a preventive measure against the development of atherosclerosis [1]. According to epidemiological food and health studies, vegetarians have a protective effect on the body over non-vegetarians [7].

The definition of vegetarian based on the International Vegetarian Union (IVU) is someone who lives by consuming a variety of vegetable products, with or without consuming milk and eggs and their processed products, but overall avoiding all animal products [8]. Vegetarians are categorized according to the type of food consumed.

The vegetarian diet has an important role in health, which is to prevent and protect a person from various diseases such as CHD, cancer, osteoporosis, diabetes, obesity, and high blood pressure. It is because the plant products have low concentration and fat absorption. Besides, plant products contain high levels of unsaturated fats, antioxidants, and fiber, also a low content of cholesterol and saturated fats [9-11].

Studies on the effect of vegetarianism on lipid profiles have been carried out, but still, yield different results. Based on the 
above explanation, it is known that atherosclerosis can be affected by many factors, including diet. Seeing the effect of diet and differences in the results of the above studies, the authors are interested in researching the description of the lipid profile in vegetarian and non-vegetarian subjects. The author chose students from the Adventist University of Indonesia (UNAI) as research subjects because students from UNAI adhere to Adventist Christian beliefs. According to Adventist belief, adherents are encouraged to avoid meat, so the authors chose UNAI students in order that the specified sample size can be satisfied. See table 1 below.

TABLE I. TYPE OF VEGETARIAN DIETS [8]

\begin{tabular}{|l|l|}
\hline \multicolumn{1}{|c|}{ Types } & \multicolumn{1}{c|}{ Diets } \\
\hline Vegan & Avoid all animal food products \\
\hline Lacto-vegetarian & $\begin{array}{l}\text { Excludes milk, include dairy product } \\
\text { e.g. cheese and yogurt }\end{array}$ \\
\hline Lacto-ovo-vegetarian & $\begin{array}{l}\text { Excludes eggs, milk, include diary } \\
\text { produce }\end{array}$ \\
\hline Ovo-vegetarian & $\begin{array}{l}\text { Excludes only eggs, include diary } \\
\text { produce }\end{array}$ \\
\hline
\end{tabular}

\section{MethodS}

We used a descriptive observational method to obtain the characteristics and description of the lipid profile levels in the two groups of subjects with cross-sectional data collection. The subjects of this study were students from the Adventist University of Indonesia (UNAI) who met the inclusion requirements, i.e. UNAI student class from 2013 - 2015 and the vegetarian subject had been on a vegetarian diet for at least the last six months. Exclusion criteria in this study were having a history of diabetes mellitus, obesity, hypercholesterolemia, or dyslipidemia; taking anti-hyperlipidemic drugs for at least the last three months; and had a smoking and drinking habits that are known based on the results of the questionnaire.

This study started with the preparation of subjects, preparation tools and materials, collecting blood, and measuring lipid profiles using a spectrophotometer. Once the lipid profile data are collected, the data will be processed and analyzed through a statistical program.

The minimum sample size for this study was 51 individuals per group of subjects, but the resulting sample size was 19 individuals per group. Sampling was conducted using the probability sampling technique using a simple random sampling approach.

The vegetarian category in the study was based on the Food Frequency Questionnaire (FFQ), which is evaluated based on dietary habits. The type of vegetarian referred to in this study was a classification of vegetarians based on the type of food eaten by vegetarian subjects which were known based on a questionnaire. Vegetarians are classified as lacto-vegetarian, ovo-vegetarian, lacto-ovo-vegetarian, and vegan. The lipid profiles measured in this study were total cholesterol, HDL cholesterol, LDL cholesterol, and triglycerides. Total cholesterol and triglyceride levels were examined using colorimetric enzymatic methods, HDL cholesterol using colorimetric precipitation and enzymatic methods, and LDL cholesterol using indirect methods using the Friedewald formula.

This research was a descriptive study. Once the data were obtained, the data were processed and analyzed descriptively to determine the mean, standard deviation, minimum value, and maximum value of the lipid profiles in the two groups of subjects. Data analysis was undertaken through a statistical program.

Researchers have paid attention to aspects of research ethics that include informed consent, anonymity and confidentiality of information received. The ethical approval was approved by the Health Research Ethics Commission of the Faculty of Medicine of Padjadjaran University.

This research was conducted at Advent Indonesia University and Clinical Pathology Laboratory, Faculty of Medicine Unjani in January 2017.

\section{RESULTS AND DISCUSSION}

\section{A. Subject Characteristics}

See table 2 below.

TABLE II. AGE OF THE SUBJECT STUDY

\begin{tabular}{|l|l|l|l|}
\hline \multirow{2}{*}{} & \multicolumn{3}{|c|}{ Age } \\
\cline { 2 - 4 } & \multicolumn{1}{|c|}{ Median } & SD & 95\% CI \\
\hline Vegetarian & 20 & 2.00 & $18-23$ \\
\hline Non-Vegetarian & 20 & 1.27 & $17-22$ \\
\hline
\end{tabular}

This study found that the median age of the subjects in both groups was the same, 20 years. The youngest subject in the vegetarian group was 18 years old, whereas the non-vegetarian group was 17 years old. The oldest age in the vegetarian group was 23 years, and in the non-vegetarian group it was 22 years. See table 3 below.

TABLE III. THE GENDER OF THE RESEARCH SUBJECT

\begin{tabular}{|l|c|c|c|c|c|c|}
\hline & \multicolumn{2}{|c|}{ Male } & \multicolumn{2}{|c|}{ Female } & \multirow{2}{*}{ N } & \multirow{2}{*}{$\%$} \\
\cline { 2 - 5 } & $\boldsymbol{n}$ & $\boldsymbol{\%}$ & $\boldsymbol{n}$ & $\boldsymbol{\%}$ & & \\
\hline Vegetarian & 5 & 36 & 14 & 64 & 19 & 100 \\
\hline Non-Vegetarian & 5 & 36 & 14 & 64 & 19 & 100 \\
\hline
\end{tabular}

Table 3 shows that most research subjects in both groups were women, up to 14 people, while men were 5 people. This result can occur because in one batch most students are female and based on information from the subjects that the vegetarian diet is practiced more by female students than male students because of their cosmetics or belief reasons. Moreover, according to the literature, it is known that in Taiwan the number of vegetarians is more followed by women than men. There are several reasons behind these results, namely that women are generally more concerned about health, appearance, and the environment than men [11-14]. 
TABLE IV. BODY MASS INDEX (BMI) OF RESEARCH SUBJECT

\begin{tabular}{|l|l|l|l|l|}
\hline \multirow{2}{*}{ BMI } & \multicolumn{2}{|c|}{ Male } & \multirow{2}{*}{ N } & \multirow{2}{*}{} \\
\cline { 2 - 4 } & $\boldsymbol{n}$ & $\mathbf{\%}$ & & \\
\hline $17.0-<18.5$ (underweight) & 5 & 36 & 1 & 3 \\
\hline $18.5-<23$ (normal weight) & 5 & 36 & 26 & 68 \\
\hline $23-<25$ (overweight) & 5 & 6 & 11 & 29 \\
\hline Total & 19 & 19 & 38 & 100 \\
\hline
\end{tabular}

Based on Table 4, the BMI of most research subjects was in the normal BMI category group. The research subjects that were included in the category of underweight were as much as a person of normal weight, 26 persons, and overweight up to 11 persons. See table 5 below.

TABLE V. TYPES OF VEGETARIAN

\begin{tabular}{|l|l|l|}
\hline \multicolumn{1}{|c|}{ Types } & \multicolumn{1}{c|}{ n } & \multicolumn{1}{c|}{$\%$} \\
\hline Vegan & 1 & 5 \\
\hline Lacto-vegetarian & 2 & 11 \\
\hline Lacto-ovo-vegetarian & 15 & 79 \\
\hline Ovo-vegetarian & 1 & 5 \\
\hline Total & 19 & 100 \\
\hline
\end{tabular}

Vegetarians are classified by the International Vegetarian Union (IVU) according to the kind of food consumed. Based on the Table 5, it can be concluded that most types of vegetarians were in the lacto-ovo vegetarian group, while the research subjects who entered the ovo-vegetarian and vegan types were the least vegetarians in this study.

These results could be due to the type of food and drink provided in UNAI's cafeteria containing lots of eggs and milk so that many subjects were categorized as lacto-ovo vegetarians. Based on the literature, vegans are widely embraced by the Maitreya Buddhist communities, because the congregation is required to be vegan. On the other hand, many people choose lacto-ovo vegetarians because they have been unable to implement a vegan diet in their daily lives due to fear of malnutrition. Because lacto-ovo still consumes animal products, so that the need for animal protein is still fulfilled which in turn can avoid the risk of developing various diseases such as metabolic syndrome, stroke, and cancer. Therefore, a lot of people choose the type of lacto-ovo vegetarian diet $[11,12]$. See table 6 below.

TABLE VI. PHYSICAL ACTIVITY

\begin{tabular}{|l|l|l|l|l|l|l|}
\hline \multirow{2}{*}{ Physical Activity } & \multicolumn{2}{|c|}{ Vegetarian } & \multicolumn{2}{c|}{ Non-vegetarian } & \multirow{2}{*}{ N } & \multirow{2}{*}{$\%$} \\
\cline { 2 - 5 } & $\boldsymbol{n}$ & $\boldsymbol{\%}$ & \multicolumn{1}{c}{$\boldsymbol{n}$} & $\boldsymbol{\%}$ & & \\
\hline Moderate & 6 & 32 & 7 & 37 & 13 & 34 \\
\hline Vigorous & 13 & 68 & 12 & 63 & 25 & 66 \\
\hline Total & 19 & 100 & 19 & 100 & 38 & 100 \\
\hline
\end{tabular}

Most types of physical activity in both groups were vigorous activity. The kind of vigorous activity they do, especially were jogging. In contrast, the lowest type of activity in the two groups was moderate activity. The kind of moderate activity that is most often carried out by both groups is a leisurely walk. Both groups were not classified as low activity.

\section{B. Lipid Profile Levels}

See table 7 below.

TABLE VII. VEGETARIAN LIPID PROFILE LEVELS

\begin{tabular}{|l|l|l|l|}
\hline \multicolumn{1}{|c|}{ Variable } & \multicolumn{1}{c|}{ Mean $\mathbf{( m g / d l )}$} & \multicolumn{1}{c|}{ SD } & \multicolumn{1}{c|}{$(\mathbf{9 5 \%} \mathbf{C I})$} \\
\hline Total cholesterol & 155.78 & 16.85 & $132-202$ \\
\hline HDL & 52.85 & 9.91 & $32.70-81.28$ \\
\hline LDL & 90.22 & 12.49 & $65.38-110.42$ \\
\hline Triglycerides & 63.56 & 14.65 & $34-93$ \\
\hline
\end{tabular}

The results of lipid profiles in the group of vegetarian subjects showed a total cholesterol, LDL, and triglyceride levels within normal limits, but there were two subjects which had the HDL cholesterol levels less than $40 \mathrm{mg} / \mathrm{dl}$. It may be concluded that they had low levels of HDL cholesterol based on classification according to NCEP-ATP III 2001 [14].

We found a vegetarian group had a good lipid profile level. This may occur because vegetarians eat many plant-derived foods and do not eat animal products. Vegetable products have low levels of fat, rich in unsaturated fats, antioxidants, fiber, and low in cholesterol, which have been shown to significantly reduce total cholesterol, LDL, and triglyceride levels without affecting HDL levels. In addition, a vegetarian diet consumes lots of fiber, which is able to bind bile acids, which contain cholesterol in the digestive tract so that it can prevent an increase in cholesterol levels in the blood [3,15-18]. See table 8 below.

TABLE VIII. NON-VEGETARIAN LIPID PROFILE LEVELS

\begin{tabular}{|l|l|l|l|}
\hline \multicolumn{1}{|c|}{ Variable } & \multicolumn{1}{c|}{ Mean $(\mathbf{m g} / \mathbf{d l})$} & \multicolumn{1}{c|}{ SD } & \multicolumn{1}{c|}{$(\mathbf{9 5 \%} \mathbf{C I})$} \\
\hline Total cholesterol & 166.47 & 33.66 & $76-214$ \\
\hline HDL & 55.21 & 7.91 & $40.20-68.90$ \\
\hline LDL & 97.30 & 30.41 & $14.09-144.25$ \\
\hline Triglycerides & 69.80 & 27.93 & $26-159.30$ \\
\hline
\end{tabular}

Based on the above data, it may be concluded that nonvegetarian subjects have a good lipid profile. This may be due to several other factors which support a person's lipid profile, such as age and physical activity. It is known that the age of the subject is still classified as young adults, which still have a good metabolism even though the subject consumes animal products [2]. Physical activity such as exercise can improve lipid profiles. Regular exercise may lower LDL and triglyceride levels and increase plasma HDL levels [5]. Exercise requires much energy so that it burns more carbohydrates, fatty acids, and proteins. The burning of fatty acids will reduce fatty acids in the blood and reduce the synthesis of triglycerides [1].

Besides to the factors of age and physical activity, based on the questionnaire we knew that the subjects' daily intake was healthy because their food was balanced between animal and vegetable products. This is supported by the theory that changes in good nutrition over several weeks can significantly lower blood lipid levels $[1,4,15,19]$. 
A limitation of this study was that the subjects must fast for 12 hours before taking the blood test. Subject compliance is difficult to monitor by us even if the researcher calls back the previous day and when the subject is taken for examination material. Another limitation of this study is that both vegetarian and non-vegetarian subject groups have been determined from the beginning so that they are not in accordance with the crosssectional principle. Another limitation is that we did not search in detail about the portion of animal protein by using a semiquantitative food frequency questionnaire. Additionally, there are many other factors that the researcher cannot control, such as genetic history and physical activity, that can influence the results of the analysis.

\section{CONCLUSION}

The characteristics of the two groups of subjects based on the most age were 20 years, based on the sex of the most subjects were women, based on BMI the most subjects had a normal BMI, based on the type of vegetarian in the group, the most vegetarian subjects were lacto-ovo-vegetarian, and based on the physical activity of the subjects most have strenuous physical activity.

The conclusion of the study is that the lipid profile of both vegetarian and nonvegetarian subjects is within normal limits. Additional research is required with a different research design (case control), more samples and a different analysis method (analytical).

\section{REFERENCES}

[1] J.E. Hall and M.E. Hall, Textbook of medical physiology. 14th ed. Philadephia: Elsevier, 2021, pp. 259-69.

[2] D.B. Marks, A.D. Marks, and C.M. Smith, Illustrated biochemistry (translated). Jakarta: EGC, 2000
[3] J.M. Adam, Dyslipidemia. In: A.W. Sudoyo, B. Setiyohadi, I.K. Alwi, and S. Setiati, editors. Internal medicine textbook. 5th ed. Jakarta: Interna Publishing, 2009, pp. 1984-92.

[4] F.J. Schoen and RS. Cotran, Blood vessel. In: Kumar Vm Cotran RS, Robbins SL, editors. Robbins basic pathology. 7th ed. Jakarta: EGC, 2013, pp. 365-78.

[5] M. Kohlmeier, Cholesterol. Nutrient metabolism. 1st ed. UK: Elsevier, 2006, pp. 511-25.

[6] A. Kumar, Significance of lipid profile assay as a diagnostic and prognostic tool. 1st ed. Internal Medical Publishing, 2012, pp. 1-14

[7] S. Rajaram and M. Wien, Vegetarian diets in the prevention of osteoporosis, diabetes, and neurological disorders. In: Joan Sabaté, editor. Vegetarian nutririon. USA: CRG Press LLC, 2001, pp. 110-29.

[8] J. Sabaté, R.A. Ratzin-Turner, and J.E. Brown, Vegetarian diet: descriptions and trensds. In: Joan Sabaté, editor. Vegetarian nutrition. USA: CRC Press LLC, 2001, pp. 3-17

[9] Susianto, The miracle of vegan. 1st ed. jakarta: Qanita, 2010, pp. 1-13.

[10] J. Sabaté and G. Blix, Vegetarian diets and obesity prevention. in: Joan Sabaté, editor. Vegetarian nutrution. USA: CRG Press LLC, 2001, pp. 91-105.

[11] Z.H. Jian, Y.C. Chang, and C.C. Lung, "Vegetarian diet and cholesterol and TAG levels by gender," PHN, vol. 18, no. 4, pp. 721-6, 2014.

[12] G. Siahaan, E. Nainggolan, and D. Lestrina, "Hubungan asupan zat gizi dengan trigliserida dan kadar glukosa darah pada vegetarian,” IJHN, vol. 2, no. 1, pp. 48- 59, 2015 .

[13] J. Maddock, Public health - social and behavioral health. 1st ed. Rijeka: Intech, 2012, pp. 83-95.

[14] M.B. Ruby, "Vegeterianism," Appetite, vol. 58, pp. 141-50, 2012.

[15] M.B. Arisman, Obesitas, diabetes mellitus, dan dislipidemia. 1st ed. Jakarta: EGC, 2013, pp. 121-54.

[16] M. Verma, P. Verma, S. Oarveen, and K. Dubey, "Comparative study of lipid profile levels in vegetarian and non-vegetarian person," IJLSSR, vol. 1, pp. 89-93, 2015.

[17] T.J. Key and P.N. Appleby, Vegetarianism, coronary risk factors, and coronary heart disease. in: Joan Sabaté, editor. Vegetarian Nutrition. USA: CRC Press LLC, 2001, pp. 33-48.

[18] D.A. Krummel, Medical nutrition therapy for cardiovascular disease. In Mahan LK, Sylvia ES, editors. Krause's food, nutrition and diet therapy, 12th edition. USA: Saunders, 2008, pp. 833-60.

[19] National Cholesterol Education Program, Detection, evaluation, and treatment of high blood cholesterol in adult (Adult tratment panel III). Final report. National Institues of Health-NIH Publication, 2002. 